\title{
CIÊNCIA, FILOSOFIA E ARTE ESCRILEITORA NA/DA ESCOLA
}

\author{
Carolina Sperb \\ Sandra Mara Corazza \\ Luiz Daniel Rodrigues Dinarte(*)
}

\section{INTRODUÇÃO}

Este texto é um escrito pensado na/da diferença, que trabalha com a ruptura e não objetiva transmissão; com imaginação e sem representação; e com criação, sem cópia. Diferença na escola é tratada desde os processos de criação tradutória dos elementos de partida, produzidos por ciências, filosofias e artes. Diferença da escola é produzida e criadora por escrileituras criativas em/de/sobre línguas maternas, filosóficas e artísticas a partir de modos "de ler-escrever em meio à vida" (CORAZZA, et, al. 2014, p.1029). Escrileituras são entendidas como criadoras no processo educacional. Línguas científicas, línguas filosóficas, línguas artísticas da diferença, da tradução, da transcriação, “em variação contínua” (CORAZZA, 2008, p. 39).

Este texto aborda uma tradução curricular-didática-semiológica, operando fantasias imaginárias em/de Escola, relacionando-se "com o conjunto do saber e da escritura" (BARTHES, 2012, p. 9), do processo educacional-filosófico entre professores, pesquisadores, tradutores, estudantes. Tradução nos flui no sentido de que não somente traduzimos sob significados, mas também sob significações, trabalhando a matéria e a fazer criando em meio ao cenalário (conjunto de cenas e de manipulações criativas). Assim, a matéria torna-se traduzida, nesse instante, como uma escrita de um Romance, que Barthes (2005a, p. 29) dá por conceito, “o romance ama o mundo porque ele o abarca e abraça". Desse modo, agenciamos as cenas em meio à vida educacional, entre escrita romanesca traduzida em meio à vida escolar, para a produção-significação de saberes e potências da diferença e "para lutar contra a secura do coração, a acídia". Acídia aquela que a Escola comporta por meio de dependências doutrinárias de conhecimentos, formando estudantes robóticos -sistematizados em processo de formação de saberes-históricos das ciências humanas; mas consideramos que os saberes humanos-politicos-linguisticos-filosoficos-éticos-estéticos devam se mover para a criação escolar, entendidos aqui como escrileituras (CORAZZA, 2008), fantasias

(*)Carolina Sperb. Universidade Federal do Rio Grande do Sul. E-mail: ccsperb@gmail.com Sandra Mara Corazza. Universidade Federal do Rio Grande do Sul. E-mail: sandracorazza@terra.com.br Luiz Daniel Rodrigues Dinarte. Universidade Federal do Rio Grande do Sul. E-mail: dionisio.z@gmail.com 
de escritura, imaginários, pensalidades (multiplicidade de pensares) e fantasiadas-maquinadas por meio-fluxos de ciência, filosofia e arte (DELEUZE; GUATTARI, 2010). Esses pensadores da diferença introduzem a ideia de que ciência opera com funções enquanto filosofia se produz em conceitos múltiplos e, enquanto funções-conceitos, ganham afetos e ações em meio à realidade múltipla. "As multiplicidades são a própria realidade, e não supõem nenhuma unidade, não entram em nenhuma totalidade e tampouco remetem a um sujeito" (DELEUZE; GUATTARI, 1995, p. 8). Em tradução contemporânea, pensamos a escola em seu funcionamento, em seu caráter de multiplicidade curricular-didático-potente "exercida por meio de um processo criador de verdades (imanentes), valores (não-representativos), sujeitos (pré-individuados) e poderes (provisórios)" (CORAZZA, 2012, p. 238). Assim, como educadores da vida contemporânea, ou seja proustianamente "biografólogos" (BARTHES, 2005b, p. 172), como escritores de vida, inventamos o cenalário curricular-didático em educação, isto é, uma ação de educar, não em nome próprio. Caso optássemos pela auto-nomeação, atribuindo lugar ao educador-autor, estaríamos fixando signo e conceito. Mas operamos de forma diferente: escrevemos em atos que movem cenários em espaço escolar e onde flutuam cenas em línguas semiológicas-semióticas-filosóficas-literárias-romanescasartísticas; esses cenalários se movem por meio de Professores e Estudantes da Educação BásicaSuperior. Pois então, trata-se de "uma escritura da consciência de tal desejo criador na área da educação; desde que, ao exercer o ofício de educar, muitas coisas funcionam" (CORAZZA, 2016, p.1). Jogamo-nos à função escrileitura tradutória em/de línguas maternas para a criação de pensamentos da diferença, não da repetição dogmática. Desde sempre, renovadores-jogadorestradutores da Escola escrileitora-gestual. Este (e próximo) palco cenalário discute e torna público os estudos filosóficos-artísticos dedicados às línguas fluidas, culturas fruídas e artes gestuais por meio de sinalidade (língua de sinais, videoteca).

\section{CENALÁRIO VITAL}

É um espaço com arquitetura marcadamente barroca, onde circulavam professores, gestores, estudantes alegres, em ambientes escolares como: o espaço da videoteca, espaço de livros espalhados em toda parte, com direito a um travesseiro e puf, bem como lugar para sentar, ou para deitar a cabeça em "vôo livre da imaginação" (BENJAMIN, 2012, p. 51). Professores formados em curso interdisciplinar de filosofias da diferença, gestores formados em curso do capitalismo em movimento; em diferença, do novo Estado em si mesmo. Estudantes, formandos em grade curricular transversalizada de ciências, filosofias e artes. Certa vez, reuniram para o debate Escrileituário em/de Libras, onde reúnem sinalizadores ou signadores (DINARTE, 2016) 
produzindo tradução e transcriação em diferentes áreas humanas de conhecimento e modalidadesmultiplicidades (e vice-versa) de criação. "Não reconhecemos nem cientificidade nem ideologia, somente agenciamentos. O que existe são os agenciamentos maquínicos de desejo assim como os agenciamentos coletivos de enunciação" (DELEUZE; GUATTARI, 1995, p. 33). O evento-debate inventário funciona com docentes e discentes de outras instituições, a pesquisadores e professores das áreas de Educação, Letras e Filosofia. Desde a perspectiva da diferença, era fabricada uma filosofia de pesquisa-ensino-extensão, relação indispensável de se educar em meio ao viver, onde operam, por escrileitura, tradução e transcriação (CORAZZA, 2013) com as matérias originais, advindas da Ciência, da Filosofia e da Arte (DELEUZE; GUATARRI, 2010). De outra perspectiva política-ética, o espaço garantia a acessibilidade a TILS (tradutores-interpretes de língua de sinais) aos Surdos que abarcam nos mundos de significação em sua língua materna, Libras, a presença de Guia-intérpretes aos Surdocegos, já que estes sentem significações por meio de tato, tela disponível com transcrição de português aos Surdos que leem-escrevem maternamente em mundos letrados. Entra em ato, a inauguradora do espaço, convidada do Escrileiturário da diferença:

- Bons dias! Estamos novamente, novos em criação. Penso em falar sobre noção de língua maior e menor. Minoria e maioria. Primeiro, estamos diante de nomes e de idiomas, como Libras e português, que são línguas de expressão de mesmo status. Dentro dessas línguas, movem-se línguas maiores e menores. Línguas maiores são de seguimento de conceitos produzidos por autores do passado e obras fantasmáticas (BARTHES, 2013). Para Deleuze (1999, p.38): "Uma língua menor só comporta um mínimo de constante e de homogeneidade estruturais. Não é contudo uma salada, urna misturada de dialetos, visto que ela encontra suas regras na construção de um continuum”. Aqui assumimo-nos autores contínuos de línguas menores, que são como respiração/inspiração e violência/paz ativa de signos "como línguas de variabilidade contínua -seja qual for a dimensão considerada: fonológica, sintática, semântica ou até mesmo estilística (DELEUZE, 2010, p. 38)”. Isso é uma obra de novidade e não de repetição da repetição. Podemos considerar pensamento da diferença. Diferença pura. Em classes de palavras, nome substantivo que adjetiva pureza. Pureza não quer dizer cópia. Quer dizer criação. Transcriação. Teorias novas, ensaios filosóficos, teses eisaiceanas... - Kandra suspirou um leve ar e decidiu terminar a sinalização, fechando alguns papéis. E fez um gesto delicado como abrisse espaço ao outro começar.

- Grato, parceira. Resisto mais uma vez nas suas teses eisceanas, que derivam inicialmente de noções espaços, imagens, signos e conjugam como EIS, funcionando expressão de linguagem, espaços-imagens-signos de Ciência variam e invariam conforme nossas habilidades de criar. EIS de Filosofia se expressa, em linhas expostas e não expostas, a cada vez que agimos por pensamento da diferença gestual e reagimos por outro pensamento, que vai se diferenciando dessa vez e daqui. Isso 
se resulta em EIS artistador, composicionalmente com AICE (autoria, infância, currículo e educador), tomemos autoria por EIS, criemos infâncias de linguagem, tornemos produção curricular desde o pensamento da diferença. Nesse caso, é possível manipular o pensar de que língua materna é língua portuguesa para alguns, língua de sinais brasileira para outros, língua filosófica, para uns...ensino de língua portuguesa, para alguns, é "preciso" problematizar metodologias, métodos, caminhos pedagógicos, orientações curriculares; para nós, é preciso inventariar métodos de criação, subverter caminhos, não orientação acadêmica, sim orientação filosófica - e não falo de área de conhecimento. Dizem Deleuze e Guattari, filosofar é criar conceitos. Pontos-traços de currículo partem de filosofias da diferença e repartem nossos aprenderes e pensares, ou vice-versa, pensar aprendendo, aprender pensando. Quando se inclui Filosofia como área/temática curricular de conhecimento humano, é preciso tratá-la como conjunto tradutório de plano de referência; de composição; e de criação, como dizem Deleuze e Guattari (2010). Quando inclui-se Semiologia, indica aprendizagem e ensino de ciências pensamentais, filosofias conceituais e artes de linguagem. Disciplinação criativa de signos e conceitos de tradução, sempre imediata, regrada "por uma espécie de evidência que lhe salta aos olhos, como o estalo do Imaginário" (BARTHES, 2013, p.42). Aqui estamos sob o escrileiturário, não procuramos fazer críticas em nome de Educadores de cópias-ememórias e passadores de histórias. Para nós, pensadores de filosofias e criadores de conceitos, produzimos mundos, pensamentos e saberes de difusão e fruição: Libras, língua brasileira de sinais, língua de sinais brasileira, língua visual, língua gestual, língua tátil, língua escrita, escrita visual, visão linguística. Desse modo, é uma "possibilidade de uma dialética do desejo, de uma imprevisão do desfrute: que os dados não estejam lançados, que haja um jogo" (BARTHES, 1987, p. 9). Vimos os conceitos fixos de que língua materna é uma língua de código transmitido pela linhagem familiar, que língua materna é o português, etc. Nada disso, longe daqui. Por aqui, reagimos por jogos de signos, como línguas maternas e filosóficas, que devem ser vistas como conjunto de signos e conceitos escrileiturários e tradutórios. -Ligeiramente desceu da cadeira, pegou-se esperando, Kuiz pegou também o lençol e bebeu segurando firmemente a garrafa de chá. Karol o observa, visualizando-o como um grande mestre tradutor, e posicionou-se ao público presente:

- Diante da obrigatoriedade de se incluir no currículo da educação básica, o ensino de artes, dança, música e teatro, por meio da Lei $\mathrm{n}^{\circ}$ 13.278/16, começamos a pensar métodos curricularesdidáticos a partir da própria perspectiva gestual? Disciplina de Artes que inclui dança, música, teatro, pintura, literatura deveria ser criada sob a perspectiva ética-estética, dizia Foucault. Temos música, dança, teatro em nossa estrutura de escola, mas não são temas "sequenciados" nos processos de aprendizagem e significação, ocorrem (in)voluntariamente, traçados ao mesmo tempo e no mesmo instante. Como podemos interdisciplinar com o ensino de português, ou seja, de 
palavras? Ensino de sinais, ou seja, de Libras? Ensino de filosofia? Ensino de semiologia? Sim, você aí. -Apontou Karol com mãos direcionando à pessoa que estava querendo sinalizar a complementação, chamada de Karlos:

-Como teria sido uma natureza tradutória e criativa do conhecimento a-sistêmico, para além daquilo que se tem reproduzido desde o ensino de sistemas históricos-pensamentais-conceituais, seja na área de filosofia, de literatura, de arte, de português? Uma certa pessoa diz: -português? Ora acho fundamental aprender regras gramaticais. Outra responde: -regras gramaticais não valem quando pedem para aprender que palavra é surgida em tal classe gramatical, somente valem quando estudamos pragmaticamente a palavra, que não represente conceito fixo, e que provoque imaginação signal (DINARTE, 2016). "Reporta o movimento a "corpos" substantivos), isto é, a objetos rígidos que vão servir de móveis ou vão ser movidos, a ação reporta o movimento a "atos" (verbos) que serão o desenho de um termo ou de um resultado supostos" (DELEUZE, 1985, p.78). Fixidez de conceitos inventados por outros, não é bem assim conosco, na grade curricular. Fixar signos de criação, como se fosse produzir um processo de significação. Podemos pensar como sentido significado de fixar-firmar-animar. Animar algo que é objeto-sujeito-imagem. Mãos de se sinalizar, mãos de se escrever, mãos de se digitalizar, bem à frente, diante da mania de manipular criatividade-novidade. Canso-me desde o pensamento da repetição. Animo-me sob um pensar da diferença. Cito Barthes (2013, p. 41-42): “O semiólogo seria, em suma, um artista (essa palavra não é aqui nem gloriosa, nem desdenhosa: refere-se somente a uma tipologia): ele joga com os signos como um logro consciente, cuja fascinação saboreia, quer fazer saborear e compreender”. Que inventemos uma tipologia de signos que nos desprendem. Biografemário, cenalário, sinalário, palavrário, didaticário, curriculário, tradutórios. Identitário? Como diz Barthes (2013, p.31): “é essa desconstrução de linguística que chamo, quanto a mim, de semiologia”. Reconstrução, construção nova desde sempre. - Terminou, visualizando outra pessoa se posicionar e ajeitar folhas e expressou um sinal para que prosseguisse:

-Obrigada, Karlos, estou situado sob a alcunha de professor de História, as perguntas que vocês fizeram, fazem-me questionar também. Enquanto dou aulas de História, também considerome professor de Libras, de português, de arte de linguagem...no momento, estamos criando videoteca, considerando aulas curriculares-didáticas...produção viva de sinalário, librando filosofias e artes... ao mesmo tempo, ativamos também palavrário, colocando legenda na tela, percebe-se estruturas gramaticais e conceituais difusas entre línguas expostas. Esses métodos são chamados, por Barthes, de biografemáticos. Para nós, podemos considerar diários biografemáticos, Dia é o momento. Bio é um viver. Grafema é ação. São derivados como escrita-leitura-obra-vida produtora de pensamento. Que conceito é esse, neste momento? O que está em jogo? diria Foucault (1999). 
Todo dia, dia todo; meio dia; meia noite, se escreve-traduz-reescreve. Escrever certos signos, traduzir os parciais e reescrever outros signos. Signos foucaultianos em signos semiológicosestéticos de Barthes. Signos de ciências, de biografemas. Signos de criação, de produção desejante em Deleuze e Guattari (2011). Foucault e Barthes se conheciam, trabalhavam como professores de linhas de pesquisa diferentes na Universidade Francesa (ou Colégio Francês?). Ambos mantinham amizade. Percebo suas diferenças no processo docente ao público livre. Aulas públicas, chegando os interessados em seus estudos de diferentes campos de conhecimento. A disciplina de Foucault era "História dos sistemas de pensamento", a qual ele próprio considerava entediante. A de Barthes era chamada de "Semiologia literária" que afirmava-se docente como "um sujeito incerto, no qual cada atributo é, de certo modo, imediatamente combatido por seu contrário". Desde nós mesmos, desde o pensamento da diferença, desde nossos estudos pesquisados, escrevemos-sinalizamos em deslocamento de prescrições históricas, "das vastas unidades descritas como "épocas" [temposespaços conceituais] "séculos" [ou "origens" de signos] para fenômenos de ruptura [tempos de tradução e transcriação] (FOUCAULT, 2008, p.4). -Finalizou ajeitando slides à tela e deu um sorriso largo, suspirando o ar, distraído, e logo gela-se ao visualizar expressão facial sisuda da Kandra, fazendo o gesto pulsado de "olha hora!".

Logo espalharam os povos, em direção à praça, seja para tomar um respiro, fumar um cigarro, tomar um café e etc. Algum tempo seguido, voltaram menos povos, somente docentes proficientes, em Libras, em direção ao encontro de Teacher Sign Creators, produzindo personagens conceituais e imaginárias, exercendo os exercícios de exercitar pensares e movimentos traçados em currículos didáticos da criação. Toma ato de inaugurar o tempo de ingresso ao encontro, Kuiz, de postura neutra e fazendo gesto ligeiro acompanhado com corpo musical:

-Formações discursivas e não-discursivas? Ou o presente? o acontecimento? O imediato? Tanto Foucault quanto Barthes, tanto Deleuze quanto Foucault, tanto Foucault quanto Nietzsche, tanto Deleuze quanto Nietzsche. Esses conceitos personalizados de ciências da repetição-diferença em diferença devem ousar-se. Todos eles diagnosticavam, todos nós exploramos por meio de olhares imaginários-maquinados de tempos-espaciais diferenciados. Sempre esperamos ir além. Distantes agora de "Desde tal fulano". Sempre afirmamo-nos na composição, recomposição e de(s)composição. Não gosto muito daquilo que repete a repetição da mesmidade, ao invés de alteridade, quando me perguntam qual seria método "ideal" de ensinar e aprender, mas para Deleuze (2003, p. 21): "nunca se sabe como uma pessoa aprende; mas, de qualquer forma que aprenda, é sempre por intermédio de signos, perdendo tempo, e não pela assimilação de conteúdos objetivos". Por intermédio de signos do pensamento da repetição, produzimos um outro intermédio de signos e criamo-nos aqui, escrevendo-sinalizando em vida. Potência de vida. Potência materna- 
linguística-filosófica. Intermédio de signos da repetição-diferença, potente. Intermédio de signos da própria diferença também é outra potência de signos. Ainda com Deleuze (2003, p. 21), “em arte ou em literatura, quando a inteligência intervém, é sempre depois, nunca antes: “A impressão é para o escritor o mesmo que a experimentação é para o sábio, com a diferença de ser neste anterior e naquele posterior o trabalho da inteligência" (Deleuze citando Proust). Anterior refere-se a quê? Signo, conceito, contexto? Signo que escrileiamos por significantes variáveis, conceito que traduzimos-transcriamos. E é este contexto, do trabalho inteligente, em que tornamo-nos autoresescritores-criadores. Potência morna de signos é maquinada quando tem-se relação de generalidade. Potência, motor, quando "é preciso sentir o efeito violento de um signo, e que o pensamento seja como que forçado a procurar o sentido do signo". Essa leitura é uma parte escrita de artigo solicitado por disciplina universitária chamada "Método de Transcriação Didática: a potência dos signos". Encerro-me, grata.

- Boas tardes para todos nós criadores de vidarbos! ${ }^{2}$ Signo de Escola, signo de língua materna, signo de filosofia abrangem significados e significações variáveis e invariáveis.... traduzíveis e intraduzíveis. De positividade e negatividade. De repetição da diferença e repetição da generalidade. Sabe como são nuvens? Quando olhamos conscientemente as nuvens em um céu, as manipulamos como personagens, personalizadas, de espaços, imagens, signos. Inconscientemente, nesse menor grau onde trabalha com inteligência (Proust-Deleuze), nessa língua menor, nessa linguagem linguística-menor, traduzimos diariamente nuvens de pensação-pensamento, de açãoacontecimento, nuvens moldadas, nuvens inventadas, nuvens representadas da Mesmidade. Podemos traduzir nuvem como figura. -Ficou-se silenciosa, Karol, indo em direção a clicar o link que estava disposto no Power Point, sinalizando que mostraria só primeiros minutos do início do vídeo <https://www.youtube.com/watch?v=0QSd0EG1qQI>.

- Viram as semelhantes figuras da caverna-escola? Conhecimentos passados e exclusivosfinitos a conhecimentos intermediários da diferença. Isto deve ser mais exposto do que daquilo. Isso é a imagem da Diferença. Distantes de Escola da repetição de tradição, próximos da Escola da repetição de tradução. Currículos didáticos da diferença, não da repetição. Linguagens linguísticasimaginárias da diferença, não da repetição. Com Corazza (2014, p. 15): “as línguas são diferenciais e que o seu trânsito - das culturas aos currículos; destes, às aulas; e de volta, outra vez, às culturas requer diálogos entre as línguas; com a condição que cada uma se torne dupla de si mesma”. Tornar duplicidade ao escriler. Tornar triplicidade ao escrever-ler-nós por meio de linguagem instrumental

2 (CORRAZA, et al, 2015, P. 11), "vidarbo como um programa operatório para texto, obra e vida-implicadas na escrita
e pesquisa em educação-enquanto Noções compostas com a escritura e o neologismo "biografema" de Roland Barthes".

Revista Teias v. 18, n. 50, 2017 (Jul./Set.): Conversas sobre formação de professores, práticas e currículos 
da diferença e não da repetição "assegurando dotação de provisoriedade e de imanência às matérias de arte, da filosofia e da ciência" (CORAZZA, 2014, p. 15). Certa vez, perguntaram-me como teria sido o papel do livro didático no planejamento e no ensino de língua materna, respondo que "se ninguém pedir e ninguém oferecer essas receitas, teremos, talvez, afastado o extremo tédio que cansa a professoralidade e as besteiras disseminadas sobre metodologia, didática, currículo" (CORAZZA, 2012, p. 241). A respeito do ensino de Saberes formados da universalidade temática, seria tedioso aquele gesto que "vai planejar, preparar e desenvolver a aula, como se ela estivesse vazia; tampouco vai se restringir à tarefa de, tão-somente, prever objetivos, conteúdos, atividades, recursos, avaliação" (CORAZZA, 2012, p. 237). Na própria situação do ensino de filosofia, é preciso primeiro borrar, raspar, rachar, rasgar, inventar, criar, ousar em campos do vivido; em espaço-tempo operatório que funciona mediante a organização de procedimentos tradutórios dos conceitos de Diferença com foco no currículo e didática da tradução, para (des)composição de espaços, imagens e signos e recomposição de autorias e obras vitais, em tempo do acontecimento... -Cansaram as mãos e logo descansam, visualizando outra colega se posicionar:

- Obrigada por mexer-me, grata por vossa atenção. Algo gesto-visual em teu texto anterior me direciona na espacialidade-racionalidade de que "a verdade não é descoberta por afinidade, nem com boa vontade, ela se trai por signos involuntários (DELEUZE, 2003, p. 15). Imaginemos línguas maternas. Que conceitos visualizamos? Ou manipulamos com significações últimas? Línguas não maternas são as impossibilidades de escriler? Possibilidades intraduzíveis? Não familiarizar com ciências e familiarizar com filosofias científicas e artísticas? Vejamos com Deleuze e Guattari (2010, p. 164):

A ciência e a filosofia seguem duas vias opostas, porque os conceitos filosóficos têm por consistência acontecimentos, ao passo que as funções cientificas tem por referência estados de coisas ou misturas: a filosofia não para de extrair, por conceitos, do estado de coisas, um acontecimento consistente.

Então, em nossos acontecimentos moventes, criamos o bem do arquivo, produto e produtor de conceitos infinitos "diretamente naquilo que permite e condiciona o arquivamento só encontraremos aquilo que expõe à destruição e, na verdade, ameaça de destruição, introduzindo a priori o esquecimento e arquiviolítica no coração do monumento. No próprio "saber de cor"” (DERRIDA, 2001, p. 23). Línguas maternas, linguagens familiares de signos, conceitos e significações derivadas, compostas e últimas, que permitem-nos exercer o papel de escrileitores dos currículos e didáticas da tradução. - Encerrou-se e fez lançou um piscar de olhos ao próximo, indicando para que se tomasse ator da cena: 
-Gracias. Trabalhamos como signadores discentes de "Currículo e Didática da tradução: toda invenção precisa de um arquivo". Toda invenção começa com um arquivo? Arquivo conceitual criado por autores da diferença? Arquivo mundial-real? Arquivo imagético? Algo arquival além de Filosofia? De História? pego um ponto-signo de Deleuze. Barthes. Corazza. E os demais da heterodoxia de textos. São eterna possibilidade de inscrever signos e de escriturar sentidos. Ousar, subverter, reverter alterações de codificações para significações; de sistemas semióticos-históricos a sistemas de línguas de fluxo. Passagem escrita acadêmico-científica a passagem escrileitorafilosófica-artística. Ora, até aqui em exercícios maquinários, em dobra criativa de práticas de leitura e de escritura. Atos de ler e de escrever. Aqui, novo ato escrileituário. Funções sociais, culturais, comunitárias, grupais e políticas rachadas da "diferença em si mesma e a relação do diferente com o diferente, independentemente das formas da representação que as conduzem ao Mesmo e as fazem passar pelo negativo" (DELEUZE, 1988 p. 8). Toda invenção termina com um outro arquivo, seja o que for não somente de signos letrados, signos gestuais, signos imagéticosmovimento, signos imagéticos-tempo, como vocês, sem audição, mas com a visão, como racham arquivos? Por meio de sinais, ou de palavras? Escrevo-leio-me romanceada. Vocês, leitores de cenalários. Daqui cenas de repetição. Não generalidade. Semelhanças equivalências. Daí, Cenas da Diferença e cenas do Fantasma. Algo vago passou pelo pensar: Barthes disse algo conforme o dia, conforme a página. É isso. Conforme o aqui. Talvez eu repita “aqui, aqui e aqui”. Influência visualgestual-imagética? Aqui, lá, aí. Mas como estou escrevendo o ato de traduzir por meio de um aqui, através de teclado, sentindo um Tum Tum Tum, algo breve de produção lexical-representação, mas nunca de completude de sentido. "Trata-se aqui, a partir do exergo, da violência do próprio arquivo, como arquivo como violência arquival" (DERRIDA, 2001, p. 17) e "o arquivo trabalha sempre a priori contra si mesmo". (p.23). Nossa escola é difusa, entre ciências, filosofias e artes em perspectiva da diferença. Bem distantes daquela que é composto de academismos. Barthes (2005b, p. 307) extrai citação de Foucault: "se ponham de lado os velhos métodos acadêmicos da analise textual, e todas as noções que derivam do prestígio monótono e escolar da escrita”. Outro Barthes (2013, p. 26) diz que "uma língua, qualquer que seja, não reprima outra: que o sujeito futuro conheça, sem remorso, sem recalque, o gozo de ter a sua disposição duas instâncias de linguagem, que ele fale isto ou aquilo segundo as perversões, não segundo a Lei”. Por isso ignoramos Leis Curriculares e as inventamos em composição com didáticas da filosofia. Encerramos ainda com mistério... Escrileitura leve. Escriturário flexível. Escrileitora de pesquisa-+ensino+extensão. Aos queridos docentes da diferença, procurem ali no cantinho-mesa de livros, peguem e distribuam em seus meios, os papéis impressos de divulgação do próximo evento onde tratam-se de noções literárias-filosoficas-éticas de pensadores e neste evento, espero encontrarmos criando ainda outros 
pensares e aprenderes no processo curricular-didático da diferença e da tradução. Temos arquivos primários da diferença para criarmos textos e vidas nas perguntas da Corazza (2016, p. 2): “Como se dão as ações de ver, falar, escrever, interpretar e traduzir de maneira curricular e didática? Como ocorre a produção de informes didáticos e a irrupção de novidades curriculares? Para criar em Didática e em Currículo, em que medida necessitamos de outros processos, como os literários, cinematográficos, musicais, plásticos, científicos, filosóficos?". No encontro próximo, dançamos por jogos curriculares-didáticos da transcriação e por jogos intraduzíveis. Para públicos que vieram primeira vez neste espaço, informo que este evento é uma das ações de extensão vinculadas ao Projeto de Pesquisa de Produtividade do CNPq, nível $1 \mathrm{C}$, "Didática da tradução, transcrição do currículo: escrileituras da diferença”, iniciado em 1/3/2015 e com previsão de término para 28/2/2019. Trabalho em composição de pesquisa-ensino-extensão. Muito mais distante de caracterizar se é isso uma pesquisa originada.se é este ensino Correto. Se é esta Verdade? Mais perto de experimentadores no sentido em que escrevermos para transformar a nós mesmos e não mais produzir a mesma coisa de antes. Assim, que seja corrente neste tempo exposto. Então, como são nossas funções em instantes: como construir signos visuais (de própria Libras) de "didática da tradução"? "transcriação curricular"? Desculpem o tempo abusado, retornemos à sinalidade de Libras no encontro e até logo! -Sorriu a atriz do cenalário, riu-se escritora daqui (deste Texto) e viu-se a transformação em resultados "de escolhas e mediação, lembrança e escrileitura dos signos, imagens e espaços traduzidos: inicialmente, da ciência, da arte e da filosofia pelos currículos; e, daí, para o drama da cena didática da aula; e de volta aos currículos; e, destes às culturas; e tudo de volta outra e outra vez" (CORAZZA, 2014, p. 6).

\section{REFERÊNCIAS}

BACHELARD, Gaston. A Poética do Espaço. Tradução: Antônio da Costa Leal e Lídia do Valle Santos Leal. Coleção Os Pensadores. São Paulo: Abril Cultural, 1979.

BARTHES, Roland. A preparação do romance I: da vida à obra. Tradução Leyla Perrone-Moisés. São Paulo: Martins Fontes, 2005a.

BARTHES, Roland. A preparação do romance II: a obra como vontade. Tradução Leyla Perrone-Moisés. São Paulo: Martins Fontes, 2005b.

BARTHES, Roland. Elementos de semiologia. Tradução de Izidoro Blikstein. 19.ed. São Paulo: Cultrix, 2012.

BARTHES, Roland. Aula: aula inaugural da cadeira de semiologia literária do Colégio de França, pronunciado dia 7 de janeiro de 1977. Tradução e posfácio de Leya Perrone-Moisés. São Paulo, 2013. 
BENJAMIN, Walter. Rua de mão única. (Obras Escolhidas v.2) Tradução Rubens Rodrigues Torres Filho e José Carlos Martins Barbosa. São Paulo: Brasiliense, 2012.

CORRAZA, Sandra Mara. Os cantos de Fouror: escrileitura em filosofia-educação. Porto Alegre: Sulina, Editora da UFRGS, 2008.

CORAZZA, Sandra Mara; RODRIGUES, Carla Gonçalves; HEUSER, Ester Maria Dreher and MONTEIRO, Silas Borges. Escrileituras: um modo de ler-escrever em meio à vida. Educ. Pesqui. [Online]. 2014, vol.40, n.4.

CORAZZA, Sandra Mara. Didaticário de criação: aula cheia, antes da aula. In: XVI ENDIPE: Encontro Nacional de Didática e Práticas de Ensino. Anais... Campinas, SP: 23 a 26 de julho de 2012, FE/UNICAMP, Disponível em: <http://www.infoteca.inf.br/endipe/smarty/templates/arquivos_template/upload_arquivos/acervo/docs/0023s.pdf> Acesso em 05 out.2016.

CORRAZA, Sandra Mara. O que se transcria em educação? Porto Alegre: UFRGS, 2013.

CORRAZA, Sandra Mara. Didática da tradução, transcriação do currículo: escrileituras da diferença. Projeto de Pesquisa (Produtividade), apresentado ao CNPq em julho de 2014 e para início em 01 março de 2015 e término em 28 de fevereiro de 2019. 41p. (Texto digitalizado).

CORRAZA, Sandra Mara. A vontade de potência do professor-artistador: currículo e didática da tradução. Trabalho encomendado do eixo 19 Educação e Arte. Reunião Científica Regional da ANPED. UFPR, Curitiba, 2016. Disponível em: <http://www.anpedsul2016.ufpr.br/wp-content/uploads/2015/11/Eixo-19-Educa\%C3\%A7\%C3\%A3o-e-Arte.pdf.> Acesso em 05 out.2016.

DELEUZE, Gilles. Cinema 1: a imagem-movimento. São Paulo: Brasiliense, 1985.

DELEUZE, Gilles. Diferença e repetição. (Trad. Luiz Orlandi, Roberto Machado.) Rio de Janeiro: Graal, 1988.

DELEUZE, Gilles. O ato de criação. Tradução José Marcos Macedo. Em: Folha de São Paulo, Caderno Mais! 27 de junho de 1999, p. 4-5. Disponível em: <http://acervo.folha.com.br/fsp/1999/06/27/72//662914>. Acesso em 5 out.2016.

DELEUZE, Gilles. Sobre teatro: Um manifesto de menos: O esgotado. Tradução Fátima Saadi, Ovídio de Abreu, Roberto Machado. Rio de Janeiro: Jorge Zahar Ed., 2010.

DELEUZE, Gilles; GUATTARI, Félix. Mil platôs: capitalismo e esquizofrenia. Tradução de Suely Rolnik. São Paulo: Editora 34, 1995, vol. 1.

DELEUZE, Gilles; GUATTARI, Félix. O que é a filosofia? Tradução Bento Prado Jr. e Alberto Alonso Muñoz. $3^{\mathrm{a}}$ ed. Coleção Trans 34, 2010.

DERRIDA, Jacques. Mal de arquivo: uma impressão freudiana. Tradução Cláudia de Moraes Rego. Rio de Janeiro: Relume Dumará, 2001.

DINARTE, Luiz Daniel Rodrigues. Congresso dos Signais: didática filosófica do gesto. Proposta de Tese de Doutorado. PPGEdu-UFRGS. Porto Alegre, 2016. $111 \mathrm{f}$.

FOUCAULT, Michel. História da sexualidade 1: A vontade de saber. Rio de Janeiro: Graal, 1999.

FOUCAULT, Michel. A arqueologia do saber. Tradução Luiz Felipe Baeta Neves. Rio de Janeiro: Forense Universitária, 2008. 


\section{RESUMO}

Este Texto tem como proposição imaginar-manipular o cenalário escolar, lugar onde é possível criar através de ciências novas e ações diferenciais, em educação para didática e currículo, com os modos tradutórios e de transcriação (CORAZZA, 2013) em Educação. Isto é realizado através/entre/com Roland Barthes (ciências de signos e significações), Jacques Derrida (arquivos últimos), Gilles Deleuze e Félix Guattari (criação de conceitos e produção de afecções/efeitos), Sandra Corazza (escrileituras e escritores da criação) e eternos estudantes de Educação. O método de criação (meio-do-caminho) é produzido e produtor em cenalários romanescos (BARTHES, 2005a e 2005b). Formas fantasiadas criadas por personagens conceituais e tempos/espaços infinitos. Mundos de criação inventados na/da Escola.

Palavras-chave: Ciências, filosofias, artes.

\section{ABSTRACT}

This text has as a proposition to imagine-and-manipulate the school scene collection, which is a place where is possible to create through new sciences and differential actions, in education for didactics and curriculum, with the translational and transcreational (CORAZZA, 2013) modes in the field of Education. It is done through/between/with Roland Barthes (signs and meanings sciences), Jacques Derrida (last archives), Gilles Deleuze and Félix Guattari (creation of concepts and production of affections/effects), Sandra Corazza (writereadings and writers of creation) and eternal students of Education. The creational method (mid-way) is produced and produce itself in Romanesque scene collections (BARTHES, 2005a and 2005b). Forms conceived through fantasy and created by conceptual characters and infinite times/spaces. Creative worlds invented in/from the School.

Keywords: Sciences, philosophies, arts. 